\title{
ASPECTOS PEDAGOGICOS EN ALGUNOS HOGARES INFANTILES DEL INSTITUTO COLOMBIANO DE BIENESTAR FAMILIAR EN BOGOTA
}

Por María Cristina Salazar ( $\left.{ }^{*}\right)$

\begin{abstract}
"Los niños serán recibidos en los jardines infantiles desde que comiencen a caminar, y serán enseñados para que nunca hieran a sus compañeros de juego $y$, por el contrario, se esfuercen por hacerlos felices. Este sólo principio podrá erradicar todos los errores que han mantenido al mundo en la ignorancia y en la miseria".
\end{abstract}

Robert Owen, 1812. El libro del nuevo mundo moral.

Es posible que si viviera en 1985, Owen hubiera expresado este mismo pensamiento de otra manera; pero quizá continuaría subrayando hoy, como lo hizo hace casi 200 años, la importancia de la educación para los niños pre-escolares, como fundamento de un mundo justo y libre para todos. Defensor de los derechos de los niños, Owen no sólo estableció el primer jardín infantil de la Gran Bretaña para los hijos de sus trabajadores en el molino de Nueva Lanarck, sino que llevó a cabo varias campañas en favor de una legislación que regulara, y aun impidiera, el empleo de los menores de edad en las fábricas textiles, y hasta quiso extender sus programas a México durante una visita a Estados Unidos en 1823. El bienestar de los niños, según Owen, se basaba en algunas ideas sencillas: fomentar su curiosidad, proporcionarles una alimentación adecuada, conversar con los niños y permitirles estar al aire libre. Los jardines infantiles podrían lograr en los niños un espíritu de benevolencia, confianza y afecto; sentimientos que se extenderían a la humanidad como algo natural (Morton 1962).

Aunque no es nuestro propósito en este artículo tratar sobre la evolución de la educación pre-escolar, sí queremos resaltar la importancia de esta área que consideramos debe ser prioritaria en las políticas estatales.

En este artículo sólo presentamos una parte de la investigación llevada a cabo en el sector suroriental de Bogotá, en 3 Hogares Infantiles del Instituto Colombiano de Bienestar Familiar ${ }^{78}$.

Recordemos, para iniciar este artículo, cuyo objetivo específico es presentar un análisis de la práctica pedagógica en tres Hogares Infantiles del sector suroriental de Bogotá, que el cuidado y la educación de los niños en edad pre-escolar en manos de extraños, es decir fuera del propio hogar, es un fenómeno relativamente nuevo en el país. (Cfr. Cerda 1981) Los niños de los Hogares Infantiles estatales se están desarrollando en situaciones que generaciones anteriores no conocieron ni experimentaron. Detrás de este esfuerzo estatal que no cubre sino una proporción mínima de niños — puede decirse que existe una conciencia incipiente acerca de la responsabilidad de todos los ciudadanos frente al hecho de madres trabajadoras que - - mientras trabajan- deben dejar a sus niños

\footnotetext{
${ }^{*}$ Profesora Universidad Nacional de Colombia. En la investigación participó Bettina Reis, Socióloga.

${ }^{78}$ Véase un primer artículo relacionado con la misma investigación en el No. 13 de la Revista Colombiana de Educación, Ier. semestre, 1984, en el cual se incluye una descripción de las áreas donde se llevó a cabo el estudio y una explicación de los objetivos generales del mismo.
} 
encerrados en condiciones peligrosas o malsanas, o al cuidado de otros niños, o peor aún en las calles sin protección alguna. El esfuerzo que representan los Hogares Infantiles del ICBF significa que empieza a reconocerse la necesidad de proporcionar cuidado y educación pre-escolar por igual a todos los niños, cualquiera que sea su origen o clase social, que ellos deben beneficiarse de un cuidado de tipo profesional, y que ese esfuerzo debe incluir en especial a los niños de los sectores más pobres de las ciudades y campos colombianos.

La existencia de centros pre-escolares estatales significa también que muchas mujeres (unas 10 mil o más) y algunos hombres jóvenes, muchos de ellos sin una educación formal muy amplia - la mayoría sólo tienen nivel de secundaria- ahora se hallan vinculados como jardineros a este esfuerzo estatal. Es importante conocer las exigencias que se les hacen, la capacitación que se les proporciona, y los aspectos relacionados con el cuidado que se presta a los niños en los Hogares Infantiles. ¿Se trata tan sólo de una extensión de la "función maternal"? ¿O se trata de una experiencia que engendra problemas especiales ante los cuales hay necesidad de desarrollar nuevos métodos y planes para el cuidado de los pre-escolares? ¿Cómo se han definido los objetivos de la educación pre-escolar? ¿Cuáles de esos objetivos deben enfatizarse, por ejemplo, en los sectores llamados marginales?

Los documentos correspondientes del ICBF señalan que los objetivos principales de los centros pre-escolares se refieren al desarrollo integral del niño, es decir, a su desarrollo intelectual, socio-afectivo, físico y estético. Se insiste en esos documentos y en muchas de las conversaciones que sostuvimos con funcionarios del ICBF y con los mismos jardineros de los Hogares Infantiles, que uno de los objetivos primordiales de la educación pre-escolar es el "aprestamiento" del niño, es decir, su preparación para la transición entre el hogar y la escuela primaria. Los jardineros, en general, aprueban estos objetivos y señalan que "los niños aprenden muchísimo", como lo comprueban distintos estudios llevados a cabo en Estados Unidos y en Europa sobre las ventajas de la educación preescolar para "niños de áreas marginales" (Center For Educational Research 1982; Lazar et al. 1977). Pero quizá es importante señalar que los jardineros no tenían suficiente claridad respecto a objetivos tan vitales como el desarrollo del lenguaje y de la capacidad sensorial del niño. Nosotros pensamos que si todo niño que va a un centro pre-escolar lograra expresar-se bien y con claridad mediante el lenguaje, y conociera cómo utilizar sus ojos, oídos y demás sentidos, así como dominar sus movimiento físicos, caminar, correr, detenerse, sentarse, pararse, es decir, el dominio de su propio cuerpo, estos serían logros muy importantes en términos de su vida futura, y constituyen en sí mismos un objetivo fundamental de esta etapa educativa.

¿Cuál es la relación entre los objetivos de la educación pre-escolar y la práctica real de cada día que se da en los Hogares?. ¿Cómo podemos dar una idea de la conducta de los jardineros frente a los niños que compruebe o tal vez complete la información lograda mediante las entrevistas que se hicieron con ellos?. Estas y otras preguntas, así fuera para responderlas en forma preliminar, nos llevaron a hacer observaciones in situ de las prácticas pedagógicas llevadas a cabo con algunos de los grupos de niños en los Hogares Infantiles que seleccionamos para este estudio. Esta parte del estudio se limitó bastante, por falta de tiempo principalmente, pues iniciamos las observaciones cuando llegaba ya a su término la primera etapa del trabajo de campo ${ }^{79}$.

Las reflexiones siguientes se basan en un análisis de estas observaciones.

\footnotetext{
${ }^{79}$ Se escogieron 6 grupos de distintas edades, entre los niños mayores de 3 y medio años, 2 grupos en cada Hogar.
} 


\section{Las relaciones entre los jardineros y los niños}

Es posible distinguir las conductas de los jardineros y agruparlas en unas categorías como las que proponemos más adelante, que permiten un análisis de las relaciones que se dan en la práctica entre los adultos de los Hogares Infantiles y los niños. Las interacciones entre niños y adultos tienen significación para su socialización y, por lo tanto, para su futuro. No sólo es importante el área de los conocimientos que pueden proporcionar al niño los adultos, sino que lo son también las interacciones que se dan en términos que pueden significar la modificación de la experiencia social del niño. Una sonrisa, un gesto, una indicación, una conversación entre un jardinero y un niño, pueden estar modificando las posibilidades futuras de ese niño en términos de su habilidad para relacionarse con otros. Por medio de la interacción que se da entre adultos y niños, se transmiten actitudes, modos de examinar los hechos, habilidades de lenguaje y expresión, y también prejuicios o concepciones con contenidos ideológicos diversos. En otras palabras, todo ello forma parte de la reproducción social que se da en todo proceso de socialización, tanto dentro de la familia, como fuera de ella.

Debe tenerse en cuenta que los recursos humanos en estos Hogares Infantiles son bastante limitados. Hay un promedio de 25 a 30 niños por grupo, lo cual exige considerables esfuerzos a los jardineros durante 9 o mas horas diarias. Las entidades administradoras de los Hogares Infantiles y el ICBF no le dan a este hecho la importancia que merece. Más bien, durante los años en que hemos venido observando los Hogares Infantiles - desde 1980- las exigencias sobre los jardineros tienden a crecer en términos del aumento del número de niños asignados a cada grupo. No existe una política de estímulos a los jardineros, por ejemplo, para mejorar sus condiciones laborales, o programas de capacitación, que podrían transformar las situaciones en que se llevan a cabo sus interacciones con los preescolares.

Para este análisis, hicimos una clasificación de las conductas observadas en los Hogares, tanto mediante nuestra participación en las diversas actividades de cada Hogar, como en talleres sobre la sexualidad que efectuamos con los jardineros, y en las entrevistas que llevamos a cabo con ellos durante un año y medio. Establecimos cuatro categorías generales de conductas relativas a los niños: ${ }^{80}$

\section{Administración, control, manejo}

Incluye todas aquellas conductas en que se introduce un elemento de dirección o control por parte del adulto. Por ejemplo cuando el jardinero ordena, exige, impone, señala, etc.

\section{Instrucción práctica}

Incluye las conductas que se refieren a procesos de enseñanza, como instruir, elaborar una fantasía del niño: "tú eres el lobo, ahora ven y me asustas", a asignar una tarea. Algunas de las conductas clasificadas en esta categoría pueden también dar una orientación o incluir elementos de control, por lo cual no son siempre excluyentes las categorías.

\footnotetext{
${ }^{80}$ Véase también Wood et al. 1980
} 


\section{Conversación}

Aquí encontramos intentos muy diversos por parte de los jardineros. Por ejemplo, el jardinero comenta lo que el niño dice, sin añadir ningún elemento nuevo; o repite lo dicho por el niño, o muestra acuerdo o desacuerdo con lo que expresa el niño. Todas estas conductas pueden ser interpretadas como intentos por entablar una conversación con el niño. Creemos que esta categoría se presta a una reflexión mayor. Porque conversar con niños de edad pre-escolar no es una tarea fácil. Para un niño de corta edad, la revelación de sus pensamientos y sentimientos exige un esfuerzo grande, lo mismo que para el adulto que lo escucha. Como no existe una serie de reglas fáciles para lograr la conversación entre adultos y pre-escolares, lo normal es encontrar estilos diferentes en el establecimiento de una comunicación verbal entre ellos.

No tenemos suficiente información para emprender un análisis detallado sobre este tema, pero podemos hacer algunas consideraciones que quizá despierten el interés de otros investigadores y educadores en el tema.

Vimos en algunos jardineros un intento por promover en los niños su capacidad de relatar experiencias, ideas, sentimientos, como parte esencial de su desarrollo. Por ejemplo, después de un paseo al parque o al zoológico, los jardineros procuraron que los pre-escolares hablaran de estas experiencias en el salón de clase. El jardinero en estos casos se ve por lo general obligado a hacer muchas preguntas, que propicien las respuestas de los niños, incluso mostrándoles imágenes de los animales para que los niños recuerden lo que vieron y hablen de ello.

Estos intentos señalan un interés en el desarrollo y la capacidad de los niños para expresar sus ideas, sentimientos, miedos, actitudes, necesidades, y reflejan también un deseo por parte de los jardineros de conocer y comprender a cada niño. Las conversaciones con un adulto sensible pueden proporcionar al niño la oportunidad de revivir una experiencia, de conocer otros objetos, de descubrir que lo que él dice o piensa, tiene interés para otros. $Y$ parece que existe además una correlación negativa -no sometida a comprobación en este estudio- entre conductas de control y la habilidad de lenguaje en el niño (Taylor 1972).

Una conversación verdadera, un diálogo, requiere una combinación entre el acto de hablar y escuchar. $Y$ en estos Hogares Infantiles, en general, se vuelve muy difícil el acto de escuchar por la cantidad de niños que tiene cada adulto bajo su cuidado y por otras condiciones de espacio y ruido no siempre adecuadas a una buena comunicación. En varias ocasiones se observó que los niños quieren ser escuchados, tienen algo que contar y lo quieren contar. Pero esto no es posible a veces, por la clase de concepción de la niñez que tiene el jardinero y que determina su trato con los niños. Además, se requieren condiciones específicas, entre ellas, la conciencia del adulto, frente a la importancia y la necesidad de la conversación con el niño. En varios casos se observaron conversaciones de tipo pregunta-respuesta, en que las respuestas de los niños eran monosílabas. Otras veces, varios niños intervinieron a la vez, sin que se pudiera escuchar lo que cada uno decía, y aun otras veces, por las condiciones ambientales - como las paredes demasiado delgadas de "Caminatas Blancas"-, no era posible escuchar lo que los niños hablaban.

Encontramos jardineros muy sensibles a las expresiones del niño, y vimos esfuerzos considerables en este sentido. Los niños preguntan como forma primordial de entablar una conversación con el adulto; pero a veces se observa que describieron algo, lo que estaban haciendo por ejemplo, lo que significa un mayor desarrollo de su habilidad 
lingüística, gracias al ambiente de mayor libertad para actuar en algunos de los Hogares Infantiles.

Sin embargo, en casi todos los Hogares, se observó que lo que más ocurre es que el adulto tiende a dominar la conversación, y esto lo hace a través de preguntas y respuestas principalmente. Los niños responden en forma corta. Pero también se observaron casos en que se ignora a los niños, aunque éstos hagan preguntas, o se habla por encima de ellos, como si no estuvieran presentes.

Tal vez esta clase de conducta ocurre porque los jardineros no han tenido una capacitación que enfatice la importancia del diálogo con los niños. En los que intentan ese diálogo, éste procede de un conocimiento intuitivo, de una convicción acerca de la necesidad de expresión que tiene el niño. Los jardineros, algunos de ellos, se refirieron a la importancia del lenguaje, a la necesidad que tiene el niño de aprender nuevas palabras, pero casi ninguno habló de la conversación con los niños como elemento de su socialización en esta edad. Sería importante conocer mejor lo que ocurre al nivel de las conversaciones de los niños con otros adultos, en su propio hogar. Saber si existe ese esfuerzo por establecer un diálogo, lo cual dependerá naturalmente de distintos factores.

Por ejemplo, en los sectores populares a los cuales pertenecen estos niños, abundan las mujeres jefes de hogar, cuyo día de trabajo fuera del hogar y cuyas tareas domésticas no dejan tiempo ni probablemente fuerzas, para entablar una conversación con los niños de edad pre-escolar que, como hemos dicho, es una tarea exigente.

El desarrollo y madurez de la capacidad de un niño para comunicarse dependen mucho del marco que los adultos les proporcionen para poderse expresar. Tal vez no exista suficiente énfasis en la necesidad que tiene el niño de ser escuchado. Según las observaciones hechas para este estudio, casi todas las conversaciones con los niños tienden a girar sobre el contexto inmediato del niño, sobre el niño mismo, sobre los objetos y personas que lo rodean, y a veces sobre los personajes imaginarios que el niño inventa para jugar.

\section{El Juego}

Muchas de las teorías elaboradas por pedagogos y psicólogos señalan la importancia del juego en el aprendizaje del niño. Para Freud, un niño aprende a manejar sus emociones, su ansiedad, sus sentimientos, provocando hechos o acontecimientos mediante el juego. Piaget, a su vez, señala que el juego es un proceso de asimilación en que el niño desarrolla, fija y retiene nuevas habilidades, dándole sentido al mundo para sí mismo. Y Froebel y Dewey hablan acerca de la exploración que hacen los niños, mediante el juego, de los fenómenos físicos y sociales que los rodean. Erikson se refirió al juego como mecanismo de fortalecimiento del ego del niño a medida que éste aprende a dominar su ambiente.

¿Qué es el juego para los niños en edad pre-escolar? Creemos que el juego significa una manera de pensar mientras se actúa, y es este proceso de pensamiento el que debe promoverse para que el niño aprenda a razonar, y a entender lo que otros hacen o sienten. En el juego que los niños llevan a cabo con los adultos, estos aspectos pueden subrayarse. El adulto puede proveer una presencia de apoyo, puede mostrarle al niño que está a su mismo nivel; en el juego se tienen las oportunidades para conversar sobre lo que el niño está "inventando", y el adulto puede aportar nuevas ideas, ayudándole al niño a hacer nuevos descubrimientos de la realidad. En el juego el niño puede acercarse al 
adulto, y si el juego de los niños es respetado por los adultos, si hay participación del adulto en el juego del niño, éste se siente respetado, siente que se le tiene en cuenta.

Nuestras observaciones en los Hogares Infantiles indican que mientras algunos jardineros le otorgan mucha importancia al juego con los niños, hasta el punto de que parecen estar jugando todo el tiempo con ellos, cualquiera que sea la actividad que se hallen desempeñando, hay otros jardineros que se sienten incómodos de participar en el juego de los niños, probablemente desconocen la relación entre juego y aprendizaje, o no le dan la importancia que ésta merece. Y los niños, así como ocurre frente a la conversación con un adulto, se acostumbran a que el adulto no juega con ellos, y entonces no le hacen exigencias en este sentido. Pero todo indica que los niños gozan con el papel del adulto cuando éste se involucra en sus distintos juegos, imaginarios o de otra índole. Entre algunos jardineros hay la idea de que el juego es cosa de niños, no de adultos.

\section{Limitaciones espaciales}

Es cierto que en algunos Hogares Infantiles existen limitaciones para el juego, por ejemplo, la falta de espacios adecuados. Aunque en los tres Hogares Infantiles que incluimos en este estudio hay espacios libres para el juego de los niños, y esta situación es bastante excepcional al tener en cuenta otros Hogares Infantiles, tanto del sector público como del privado, que no tienen estos espacios a pesar de que el Ministerio de Educación exige que cada centro pre-escolar tenga un área con árboles y césped (pero esta es una de tantas condiciones que no se cumplen). De modo que es una especie de privilegio para los niños el disponer de áreas libres; por ser niños que provienen de hogares cuyas condiciones habitacionales no incluyen una esfera infantil separada, ni un cuarto especial de juego, ya que su vivienda muchas veces es apenas una pieza habitada por muchas personas, en donde incluso se cocina. Los niños, por lo general, tampoco tienen posibilidad de jugar en las calles, porque aún en los barrios alejados del centro, el tráfico es abundante y son muy escasos los parques o espacios de recreación pública. Sin duda podemos afirmar que el factor espacial es uno de los principales que hay que incluir al hablar de las restricciones para el juego de los niños en los Hogares Infantiles.

\section{Limitaciones Psicológicas}

Pero también hay limitaciones de orden psicológico para el juego. Porque el juego se confunde muchas veces con la ociosidad, por lo cual muchos adultos desarrollan actitudes negativas hacia el juego de los niños. Se reprime el juego como se reprime el ocio, viéndolo como un obstáculo al desarrollo de una disciplina de trabajo.

Para muchos adultos, se trata de educar para la industria, para una actividad incesante, como se pone de manifiesto en libros diversos sobre la escuela, hasta en canciones infantiles, y en la instrucción religiosa que presenta la actividad permanente como una virtud y un deber cristiano.

Sin duda que estas concepciones diferentes se encuentran en distintas etapas históricas del desarrollo de las sociedades, y también en distintos sectores de la población.

En los Hogares Infantiles que estudiamos, en especial en el de la Picota, por la fuerte influencia religiosa que hay en él, se escuchó a las jardineras expresarse frecuentemente sobre la importancia de formar al niño mediante el "trabajo", es decir, mediante distintas 
actividades que ellas denominan como tal. Por ejemplo, ensartar, dibujar, colorear. Nada de jugar al hacer estas tareas ¡No. Se prohíbe expresamente cualquier intento de juguetear durante las etapas denominadas de "trabajo". Es entonces cuando esas jardineras se esfuerzan por exigir a los niños posturas rígidas, silencio, inmovilidad, una disposición de ánimo que refleje seriedad. En todo ello puede reflejarse un modo de impedir el juego de los niños, como también un deseo, tal vez no del todo consciente, de preparar a los niños de los sectores pobres de la ciudad, para trabajos de tipo monótono, de "utilidad", que exigen repetición, destreza manual, acatamiento, sumisión. Es decir, una educación para el pueblo que debe mantenerse dentro de límites fijados por los sectores dominantes.

En las familias de casi todos los niños de estos Hogares Infantiles, priva también una concepción anti-juego, anti-ocio. Los niños deben estar siempre ocupados, se les envía a hacer mandados desde muy pequeños, deben cuidar a sus hermanos menores, en especial las niñas, y deben ayudar en todos los oficios domésticos y también en la producción artesanal cuando existe, como en el caso de los chircales. En estas condiciones no existe la posibilidad de configurar una "esfuera del juego" dentro de la familia. Seguramente, si se hiciera una comparación con lo que ocurre dentro de las clases burguesas, habría diferencias fundamentales en lo relacionado con la concepción y las actitudes que se tienen hacia el juego de los niños.

En Colombia, no hemos estudiado ni el origen ni el significado de los juegos infantiles. Muchos de ellos, como el de la gallina ciega, el puente está quebrado, etc., nos vienen de los europeos, y tienen que ver con el ocio de la nobleza. Pues el juego es un elemento fundamental de la "cultura del ocio" descrita por Veblen, junto con la caza y el amor, en la sociedad feudal europea. La forma de vida de la nobleza es juego, se identifica con el juego.

Los juegos observados en los Hogares Infantiles son muy diversos. Se juega a arrancar la hierba, a balancearse, a coger flores, a saltar, a bailar, a disfrazarse, a cantar, a cuchichear, a abrazarse, a contarse historias, a besarse, a pillarse, a contarse cuentos, a imitar personajes, se juega a los novios, al escondite. Se juega con objetos: bolitas, bolos, dados, muñecas, el caballito de palo, los carros, pelotas, el yoyo, las pistolas. Se juega al ladrón o al gendarme, a la gallina ciega, al escondite, a las rondas, a las sillas musicales, a las adivinanzas, a las danzas, al almacén, a vender y comprar. A veces se permite a los niños jugar con el agua, o jugarretas en los lavamanos.

Hay juegos muy activos, otros que son entretenimientos tranquilos ocurren los juegos sexuales, y muchos de los juegos de los niños tienen un contenido erótico. Unos juegos se reglamentan, otros son más libres. Se juega imitando las actividades de trabajo de los adultos, por ejemplo, a poner ladrillo en el horno, a sembrar, a ordeñar, a pasear, a arriar animales, a enseñar, a la mamá, al cuidado de los niños, a barrer.

Los juegos libres consisten en que se deja a los niños elegir entre los objetos que se tienen para jugar. Algunos juguetes han sido diseñados para mantener a los niños quietos y en silencio: los rompecabezas, los bloques de madera, todos los juegos que exigen un esfuerzo de coordinación, y alguna concentración. En algunos casos, el juguete es para que el niño lo haga jugar.

Con base en esta clasificación de conductas, intentaremos en las páginas siguientes analizar las relaciones entre jardineros y niños, en los tres Hogares Infantiles. 
Estas relaciones manifiestan, en primer lugar, la concepción que el adulto tiene acerca del niño. Como ya lo hemos indicado en capítulos anteriores (Salazar 1983 y 1984) las concepciones sobre la niñez varían según el sector social, y probablemente también de acuerdo con otros factores que no hemos incluido aquí, pero que deben ser tomados en cuenta en futuras investigaciones. Tales son los rasgos de personalidad de los jardineros, su edad, sexo y origen; su propia socialización, y su experiencia educativa y laboral. Su conocimiento de teorías pedagógicas y psicológicas acerca de los pre-escolares también pueden contribuir a la manera como evalúan a los niños bajo su cuidado. Su pertenencia a una estructura laboral determinada, que a través de sus distintos miembros, reglas y prácticas ejerce una influencia cotidiana sobre sus actitudes y percepciones, no deja de tener importancia.

\section{Hogar Infantil "La Picota”}

No es sorprendente, entonces, encontrar que en el Hogar Infantil La Picota, caracterizado por una estructura jerárquica (de tipo religioso) en el momento en que se llevó a cabo el trabajo de campo para esta investigación, las relaciones de los jardineros con los niños, correspondieran a una concepción del niño que en cierto modo indican un menosprecio y una subvaloración del mismo.

Los mismos niños, en las observaciones que se transcriben en el informe final de la investigación, hacen constar que la jardinera se refiere a ellos como "niños perezosos", "niños que duermen demasiado"; que la jardinera utiliza castigos físicos, y que incluso ha excluido a los niños del Hogar Infantil por llegar tarde! Una de las jardineras, durante una sola mañana, se refirió en términos despectivos a los niños en presencia de éstos, una docena de veces por lo menos. Algunas de sus afirmaciones fueron:

— “algunos de los niños están sucios y malolientes"

- "estos niños no son tan inteligentes como otros que tuve antes"

— "ese niño es difícil, le gusta llevar la contraria" (señalándolo)

— "Pedro es muy rebelde, no se deja sancionar"

- "ese niño no habla, no quiere hablar" (el niño tuvo un accidente grave, según nos informó la misma jardinera)

- “los niños no saben escoger bien los colores"

- "ese niño lo consienten mucho en su casa"

— "a los niños no les quedan bien los dibujos".

Estas y otras frases, y el hecho de que se identifique a los niños por un número, y no por su propio nombre, reflejan un cierto menosprecio del niño, y un desconocimiento de su sensibilidad, de sus capacidades y habilidades potenciales. Es evidente que las relaciones que esta jardinera establece con los niños se resumen casi exclusivamente en una relación de control permanente, autoritaria, en donde se impone el silencio como norma privilegiada, la rigidez e inmovilidad en las posiciones del niño, la ausencia de comunicación entre los mismos niños, y de éstos con la jardinera.

En las sesiones observadas, con sendos grupos de niños de 5 a 6 años, y de 6 a 7 años, respectivamente, cada grupo con un poco más de 30 niños, en espacios muy reducidos que aproximadamente significan alrededor de $1 \mathrm{~m}^{2}$ por niño, bajo el cuidado de una sola jardinera, y con los niños sentados en el suelo por falta de un mobiliario adecuado, la conducta de los niños fue de inmovilidad, de no hablar los unos con los otros, de contestar en voz muy baja y con miedo a las preguntas que les hicimos, de no 
saber qué hacer cuando mostramos admiración o aprobación de sus tareas y dibujos, de no jugar entre sí.

Los niños no supieron cómo describir sus propios juegos; no sonrieron sino escasas veces en esas largas mañanas, mucho menos rieron o mostraron alegría; respondieron con monosílabos a las preguntas de la jardinera o de la observadora; no hicieron dibujos libres sino que rellenaron siluetas pre-dibujadas por la jardinera; hicieron recortes de acuerdo al tema impuesto de "la familia" (con mamá mona, papá protector y dos niños), imagen que no refleja la realidad familiar de los niños que provienen en una gran mayoría de hogares dirigidos por mujeres solas; demostraron miedo frente a los adultos, aún actitudes serviles, y repitieron preguntas y respuestas en coro.

Unos pocos niños manifestaron imaginación en sus juegos, pero ante todo escucharon órdenes y reprimendas: cállense, no se recuesten en las paredes, hagan silencio, no jueguen, recojan los juguetes, saluden, repitan, etc.

Con base en estas observaciones y en muchas horas de conversación con las mismas jardineras, es posible afirmar que en este Hogar Infantil, las relaciones entre adultos y niños se dan en el área de manejo y dirección principalmente, de acuerdo a la clasificación de conductas presentada en páginas anteriores. El trato con los niños fue más bien en forma colectiva que individual, debido precisamente a la gran cantidad de niños que tienen a su cargo las jardineras.

Estas escasamente manifestaron conductas que se puedan ubicar en el área de la instrucción práctica que, según nuestra clasificación, implica compartir con los niños las tareas que se hacen para lograr un aprendizaje o la comprensión de un hecho o situación. Tampoco incluyen en sus relaciones con los niños el juego, en el sentido de compartir sus juegos, o de "seguirles la corriente", cuando los niños inventan situaciones, o dan rienda suelta a su fantasía. $Y$ tampoco pudimos constatar intentos de entrar en conversaciones con los niños, de establecer un diálogo con ellos.

Pero lo importante de estas observaciones puede referirse más a que el niño responde a los adultos según como éstos se comuniquen con él. Si el niño se encuentra enfrentado de manera continua a actividades en que se le dirige, se le controla, se le maneja, su acercamiento al adulto viene a reflejar esta misma clase de interacción. Se acerca al adulto para repetir esa relación de dominio o control: el niño entonces pregunta por algo, pide un objeto o un juguete, pero no pretende jugar o conversar con el adulto. Cuando el niño tiene la posibilidad de entrar en relaciones informales, de igual a igual con el adulto, sin tanto control y dirección, como en el caso del Hogar Infantil de la comunidad de los chircales que estudiamos en este proyecto, el niño entra en estas relaciones informales con una gran naturalidad, espera que el adulto converse con él, que comparta sus juegos, que el adulto ingrese a su mundo infantil de inventos y fantasías.

Cuando el control o el manejo de los niños se convierte en la principal función del jardinero, éste puede controlar al niño en todas las actividades que se programan en el Hogar Infantil, desde el juego y la enseñanza hasta el tipo de conversación que tiene con él. Esta palabra, control, viene a ser central en la descripción de lo que pasa en el Hogar Infantil La Picota.

Podemos afirmar, como una primera conclusión, que en este Hogar a través de interacciones de control se están reproduciendo relaciones de dominación y subordinación, que niegan el desarrollo de la imaginación e impiden la creatividad de los 
niños. Se exige disciplina y orden como se expresa en diversos capítulos del informe de la investigación. Se espera siempre que el hijo haga lo que el adulta determina para él expresando así desconfianza de sus potencialidades. Son interacciones que reflejan una violencia oculta: no es la libertad, ni el desarrollo, ni la autonomía del niño lo que se respeta en estas relaciones, sino su sumisión a la voluntad de otros.

\section{Hogar Infantil Rin Rin Renacuajo}

Las observaciones llevadas a cabo en dos grupos de "Rin Rin Renacuajo", con niños de edades entre 5 y 6 años, el primero, y entre 3 y medio y 4 y medio años el segundo, señalan una serie de interacciones entre los adultos (un jardinero y una jardinera y dos observadoras) muy diferentes a las descritas para "La Picota". Son grupos un poco más pequeños, de 24 y 17 niños, respectivamente. Pero en este Hogar se advierte un ambiente de mayor libertad y de gran respeto por los niños. Los niños tienen mesas y asientos pequeños, entran y salen libremente del salón, se paran o se sientan cuando quieren hacerlo, conversan entre sí y con los jardineros, entran a la oficina de la directora.

En sus salones juegan, pelean entre sí, recortan papeles, los pegan, se untan con el pegante y gozan con ello como si fuera un juego, ayudan a los jardineros en distintas tareas como guardar, arreglar y repartir los juguetes, y servir el almuerzo. Los jardineros animan a los niños, los estimulan en forma continua: "como mejoraste", "qué bien lo hiciste esta vez", y expresiones similares. Revisan los trabajos o tareas de cada niño, juegan con ellos, dentro y fuera del salón; de vez en cuando ponen un poquito de orden, sin regañar a los niños. Enfatizan el sentido de la colectividad: "el platón es para todos", "quién le presta una crayola a Anita?". Hay una preocupación por cada niño, por animarlo, por hacerlo participar en los juegos o actividades de los demás. Los niños están interactuando con los jardineros todo el tiempo, se les acercan para hacerles preguntas o buscar aprobación, conversan con ellos de lo que están haciendo. Los niños hablaron con las observadoras sin timidez.

Puede decirse, con base en estas observaciones y de acuerdo a nuestra participación en distintas actividades del Hogar Rin Rin, que no obstante las limitaciones de estos datos para hacer generalizaciones, las relaciones entre adultos y niños en este Hogar se refieren a varias de las conductas incluidas en las distintas categorías señaladas anteriormente, sin que ellas se concentren en el área del control de los niños. No existe, como en "La Picota", un reforzamiento de las conductas de control y manejo de los niños. Por el contrario, las conductas se ubican en las 4 categorías, privilegiando relaciones de igualdad, de participación, de informalidad, y de diálogo con los niños. Estas conductas revelan una concepción del niño mucho más positiva, como ya se había señalado en el capítulo correspondiente a este tema.

Se producen interacciones que pueden significar para los niños un desarrollo de su capacidad de interactuar con otros adultos, sea en el presente como niños todavía, o en el futuro como adultos que tendrán que enfrentarse a realidades distintas a las del mundo o subcultura de la comunidad chircalera en que se ubica este Hogar. Aquí se programan actividades que reflejan un interés real por ampliar las experiencias de los niños como visitas al zoológico y al parque. Al niño se les están brindando las oportunidades requeridas para su desarrollo afectivo e intelectual. 


\section{Hogar Infantil "Camitas Blancas"}

En este Hogar llevamos a cabo observaciones con dos grupos de niños: el de 4 a 5 años con 27 niños; y el de 3 a 4 años con 20 niños.

El ambiente, como en "Rin Rin", refleja cierta libertad para los niños; éstos entran y salen de los salones, cambian de juguetes, guardan los bloques, recogen lo que haya que guardar, sin necesidad de que se les ordene hacerlo. Comparten tareas como las de servir y arreglar las mesas para el almuerzo, sin distinción de sexos, pelean entre sí, muestran curiosidad sexual, buscan aprobación y estímulo de las jardineras y de las observadoras por igual. Los niños seleccionan los dibujos que han hecho libremente para colgar en la pared los que les parecen más bonitos. Preguntan y conversan con las observadoras y las jardineras; los niños mayores manejan bien las crayolas y los lápices. Las jardineras dirigen un poco los procesos, pero dando importancia a la sensibilidad de los niños; se les corrige el lenguaje, se les responden las preguntas sobre la sexualidad con mayor naturalidad y las jardineras se expresan positivamente sobre los niños. Ellas hacen ejercicios con los niños, mostrándoles cómo hacerlos, les dan algunas explicaciones sencillas, de cómo ensartar por ejemplo, les distribuyen los escasos juguetes que hay en el Hogar permitiendo que cada niño cuente sus propios cuentos e historias, y se exprese como quiera. Promueven en el niño la seguridad en sí mismos.

Los niños juegan en conjunto, por ejemplo, construyen un tren, comparten los juguetes, juegan con cualquier objeto sencillo, como las tapas de botellas, imitan conductas agresivas o afectuosas que probablemente ven en sus casas o en la T.V. También se entretienen en juegos independientes, pero conversan bastante entre sí y con la jardinera.

Encontramos algunas conductas de manejo y control de los niños, - son conductas que nunca pueden estar del todo ausentes- pero también muchas intervenciones que se refieren a las otras categorías de nuestra clasificación, de instrucción práctica, juego, y conversación.

Como en este Hogar tuvimos la oportunidad de llevar a cabo un taller de sexualidad durante un período mayor, conocimos un poco más a las jardineras. Esto nos permite afirmar que sus diferencias de personalidad y sus diversas experiencias y antecedentes educacionales y laborales, influyen sobre las conductas que manifiestan en el trato con los niños. Nos parece percibir que hay un elemento de alienación y distancia frente a los niños ( $y$ también frente a otros adultos) que lleva paradójicamente a expresiones de control y de dominación, en las jardineras con mayores niveles de educación. Estas por sus conocimientos y su capacidad de expresión, han desempeñado un papel de liderazgo en el Hogar que no siempre se manifiesta en mejores relaciones con los niños a su cuidado, ni con los demás adultos del Hogar Infantil. Pero este es un tema que requiere un análisis más amplio y detallado, para el cual carecemos de la suficiente información.

Como conclusión, se observa que son muchas las dificultades para entablar una relación adulto-niño, cuyo primer objetivo sea la conversación con los niños a nivel individual. Casi todas las interacciones entre jardineros y niños se dan de modo colectivo en estos Hogares; las condiciones a que nos hemos referido anteriormente tienden a crear una necesidad de conductas de control, más que de participación en el juego, o de conversación con los niños, entre los jardineros las conductas de control son también reflejo de la estructura autoritaria que rige la sociedad colombiana y que tiene como efecto producir pasividad. 
Encontramos en este sentido diferencias entre las conductas de las jardineras que de nuevo reflejan concepciones diversas de la niñez. Por tratarse de jardineras cuyo interés en el niño nos parece muy real, sería una experiencia valiosa el llevar a cabo los procesos de observación sugeridos más adelante sobre sus interacciones con los niños, mediante una participación plena de ellas mismas en el proceso. Formaría parte de un proceso de capacitación que no implicaría ni esfuerzos ni una financiación muy grandes.

\section{Comentarios sobre las tendencias pedagógicas}

Puede verse en las experiencias pedagógicas observadas en los 3 Hogares Infantiles, distintas tendencias que se ubican en lo que podría llamarse el extremo tradicional de la educación, y otras que corresponden a la corriente de la educación liberadora o moderna, inspirada - así sea de manera indirecta - en distintas corrientes del marxismo y del psicoanálisis.

\section{La Educación Tradicional}

Dentro de este enfoque, la escuela viene a ser una extensión de la vida adusta del adulto, enfatizándose la auto-restricción y un sentido estricto del deber: se debe hacer lo que se nos dice, la autoridad tiene siempre la razón. Estos presupuestos se oponen a la tendencia moderna de hacer de la escuela una extensión de la tendencia natural de la niñez de investigar jugando, de aprender haciendo, y además haciendo tareas y actividades que agradan al niño.

Veamos algunas características que atañen al enfoque tradicional de la educación y que se constataron en por lo menos uno de los Hogares Infantiles: no se da importancia al sentido de identidad del niño, la seguridad interior del reconocimiento por parte de los adultos, de los que cuentan en alguna manera en la vida del niño. Como se ve en la numeración que se impone a los niños para su identificación.

El proceso de formación de la identidad en el niño conlleva una reflexión y observación mediante las cuales el niño se juzga en sí mismo a la luz de la percepción que él tiene sobre cómo otros lo juzgan. La formación de la identidad es un proceso de diferenciación creciente, y se vuelve más inclusiva a medida que el niño toma conciencia de un número mayor de personas que significan algo para él. De estas personas es que el niño espera reconocimiento, lo cual no siempre se da; más bien se dan reprimendas, se insiste en que está mal el trabajo del niño, rara vez se le estimula.

Tal vez influya en estas actitudes una subestimación por parte de las jardineras (y de la directora) de la forma como la historia de cada niño pueda restringir su destino o su futuro. Junto con ello predomina una concepción sobre el cambio que restringe aún más las posibilidades de la educación. El cambio es visto como una simple cuestión de buena voluntad, o de fuerza de voluntad ("si el niño quiere, se puede superar"), mientras que la resistencia al cambio es vista como mala voluntad, o inferioridad, o herencia en el niño.

El concepto del orden y la insistencia en él también caracterizan este enfoque tradicional. Los criterios de orden prevalecen en todo: se cumple un horario de manera estricta diariamente. Los muebles, juguetes, materiales diversos, deben estar siempre en un lugar determinado, y los niños deben mantenerlos en orden. El salón debe estar en orden, y los niños igualmente, cada uno en su puesto, quieto, inmóvil, "concentrado", en silencio. Las actividades en el día se distribuyen según un orden fijado de antemano y nadie puede modificarlo; los niños saben qué sigue después de cada actividad, y debe 
esperar a que termine el tiempo fijado para éstas, y no puede intervenir para modificar la secuencia. No tiene libertad para cambiar de actividad; debe someterse al ir y venir entre las actividades que no exigen mucho esfuerzo intelectual, como gimnasia, canto, etc., y el "trabajo", de la manera como lo ordene la jardinera.

El fin primordial de la educación pre-escolar dentro del enfoque tradicional es la aprestación para el ingreso a la escuela primaria. Pero no existe una enseñanza centrada en la auto-determinación del niño; se deja poco campo a la iniciativa del niño; aún en el "juego libre" la jardinera se constituye en el centro de atención de los niños. Y es ella quien pre-fabrica los dibujos, ejercicios, materiales de juego, y quien decide qué ronda infantil se va a cantar, qué clase de juego se va a hacer.

Las sanciones y las reprimendas se expresan claramente; pero las jardineras utilizan más bien un tono autoritario suave, no exento de cariño por los niños. Los niños probablemente aprecian una coerción suave pero firme en la aventura de descubrir que se pueden hacer cosas que ellos no habrían pensado por sí mismos. Los niños obedecen automáticamente dentro de esta clase de ambiente represivo, ya que conocen los principios y reglas del Hogar Infantil. Puede ser que no siempre entiendan las órdenes que reciben, pero sí saben que deben acatarlas como parte de los hechos que han experimentado, aunque no las comprendan. Saben que no pueden salir del salón, que a la jardinera no le gusta que pidan permiso para ir al baño "a deshoras", que no deben jugar con la comida, que deben hacer fila y obedecerle cuando ella con un dedo en los labios les pide silencio: Shhht, Shhht; que no pueden salir a la calle, y así otra serie de interminables prohibiciones. Si violan alguna de éstas, viene una reprimenda que, por lo general, basta para que el niño reacomode su conducta a lo que la jardinera espera de él.

Otro aspecto de la represión tiene que ver con la enseñanza sobre la familia y la educación sexual. La familia es vista desde una perspectiva idealista; se enseña como un valor positivo a ser mantenido, y en los cuentos, historias y actividades utilizadas por las jardineras, siempre hay referencias "al papá, la mamá y los niños que viven felices", cuando la realidad de estos niños es completamente diferente, perteneciendo la mayor parte de ellos a hogares incompletos, donde muchas veces ni siquiera se conoce al padre. No se permite que los niños hablen o pregunten sobre el sexo, mucho menos juegos de tipo sexual, ni ir juntos al baño, ni desnudarse. Los niños duermen separados de las niñas. Es obligatorio dormir durante el período de la siesta, y aunque los niños quieran hablar o jugar, no pueden hacerlo a esta hora. Las comidas también son a horas fijas; los niños tienen que hacerlo todo con una gran formalidad: "hay que estar haciendo lo que toca hacer" a cada momento del día.

Como son en realidad pocas las ocasiones que tienen los niños de comunicarse entre sí, no se dan muchas situaciones de conflicto abierto entre ellos. La jardinera interviene cuando hay alguna agresividad entre los niños; pero el gran número de niños por jardinera impide el control permanente por lo cual a veces los niños pelean un poco. Puede decirse que el niño no tiene oportunidades para experimentar cómo resolver problemas de tipo personal, ya que se le impiden a través del control de la expresión de su agresividad.

Como se desprende de las observaciones anteriores, no hay duda de que se trata de una orientación represiva autoritaria que para nada tiene en cuenta los adelantos de la psicología infantil o los conocimientos de una pedagogía más moderna.

El desempeño de las jardineras tiene como finalidad la de dirigir permanentemente a los niños, lograr comportamientos que a ellas les parezcan adecuados; incluso llegar a 
dirigir con gestos, miradas, expresiones, que los niños inmediatamente captan como "ordenes".

La relación entre padres de familia y jardineras es casi inexistente, dificultándose así la continuidad entre la educación que recibe el niño en la familia y en el pre-escolar. Esta distancia se manifiesta también en las relaciones de las jardineras con los niños, quienes deben conservar en su trato con ellas las fórmulas respuestas de "doña", o "profesora" al dirigirse a las mismas.

Debe destacarse que en esta clase de enfoque educativo existe una participación muy endeble de los padres de familia en el proceso. Ellos son vistos más bien como visitantes en el Hogar Infantil, extraños a éste; y si alguna vez se les pide su colaboración, es para aportar su fuerza de trabajo en obras que se requieren o su contribución monetaria para cubrir distintas necesidades del Hogar.

\section{La educación liberadora}

Como se señaló anteriormente, en la educación liberadora la escuela se convierte en una extensión de la tendencia natural del niño a investigar jugando, a aprender haciendo cosas que le resulten placenteras. El juego alcanza el mundo que se comparte con otros; los elementos de ese mundo se tratan coma cosas; el niño las examina, las mueve, las obliga a "convertirse" en lo que su imaginación desea, por ejemplo, en "ser el caballo", "ser el avión", etc. El aprendizaje a través del juego no sólo el mundo de la fantasía, sino el de la realidad. El juego incluye un modo infantil de dominar la experiencia social mediante la experimentación, la planeación y el compartir. A través del juego, del mundo de los juguetes y de las cosas, el maestro puede reconocer talentos especiales, llegar a conocer al niño en la expresión natural de sus sentimientos y pensamientos, ayudarle a relacionarse con el mundo adulto.

Respecto a las nociones de orden y disciplina, como se desprende de la descripción anterior, es poco el énfasis que se hace en ellas. Los niños ayudan a ordenar los salones, recogen los platos del almuerzo, ayudan a pasar los elementos como lápices y otros que se usan en las actividades pedagógicas, guardan los juguetes en los armarios, pero dentro del mismo ambiente de informalidad, y casi como si se trata de otro juego.

Se aceptan los deseos del niño, procurando satisfacerlos también para lograr su desarrollo como ser autónomo, no reprimido. Se acepta la sexualidad infantil en sus diversas manifestaciones; hay actitudes de comprensión frente a los juegos sexuales y a la masturbación de los niños, se les estimula para que conozcan su propio cuerpo. Por ejemplo, se permite la desnudez entre los niños a la hora del baño, la ida al baño se convierte como en otro juego, la masturbación es vista como algo natural.

Las observaciones que hicieron las jardineras sobre la sexualidad de los niños durante este estudio nos llevaron a proponer unos "talleres de sexualidad" que se iniciaron a mediados del año 1983, primero con las jardineras y luego con los padres de familia. Sobre el desarrollo de estos talleres incluiremos más adelante un capítulo especial, por la utilidad que ellos pueden tener en otros Hogares Infantiles. Pero puede afirmarse que los talleres hasta el momento han tenido un efecto positivo, en el sentido de que tanto las jardineras como los padres de familia (con mayor participación de las madres), han venido a aceptar las expresiones sexuales del niño, sin estarlas prohibiendo. 
Se aceptan las preguntas del niño sobre el sexo como un intento de su necesidad de aprender cómo es el mundo, cómo son los seres que lo rodean para lograr su propia identificación. Las preguntas de los niños poco a poco han venido a aceptarse como signo de progreso en el desarrollo normal del niño. Se acepta que los juegos sexuales de los niños corresponden a la naturalidad con que ellos muestran su interés por el sexo, y que mediante esos juegos el niño reafirma lo que él sabe sobre el mundo y la sociedad.

La ampliación de las relaciones sociales de los niños viene a constituirse en objetivo importante de la educación pre-escolar. Para ello se promueven relaciones informales entre los niños y todos los adultos que trabajan en el Hogar Infantil; los niños se dirigen a las jardineras por su nombre, incluso utilizando apodos cariñosos, y ellos pueden entrar y salir libremente del salón, y por ejemplo visitar la oficina de la dirección o de la administración. Se hacen paseos al zoológico, a las ferias que se celebran en la ciudad, al aeropuerto, al parque, con el fin de ampliar el conocimiento de los niños sobre la ciudad y la confianza en sí mismos. Igualmente, las jardineras consultan con los niños los cambios en las actividades que desempeñan y dan prioridad a lo que los niños quieran hacer. Todo ello fortalece la confianza que los niños logran en su propio criterio, con lo cual poco a poco se rompe la dependencia frente a sus padres. La autodeterminación, la autonomía, la independencia del niño vienen a ser valores fundamentales dentro de este enfoque educativo.

No se suprime la conducta agresiva de los niños; por el contrario, se permiten las peleas entre ellos y el educador no interviene como juez, permitiendo que el niño resuelva sus propios conflictos, y sólo interviene cuando la agresividad puede resultar en un peligro físico o psíquico para el niño. Esto permite al niño tener experiencias que le permiten enfrentarse al conflicto; se trata de que el niño llegue a comprender su propia conducta, los procesos sociales y su propia realidad. Es esta la única manera como el niño puede llegar a desarrollar una conciencia crítica, es decir, una comprensión de la realidad según una visión dialéctica. Se fortalece también la conciencia de grupo que se desarrolla en los niños; todas las sanciones, reprimendas, prohibiciones, se explican con claridad a los niños para que las comprendan y acepten.

Los educadores crean un clima emocional dentro del pre-escolar que se caracteriza por el aprecio, el afecto, la cordialidad, la comprensión. El educador orienta a los niños, más bien proponiendo, sugiriendo, encauzando actividades, y rara vez, dando órdenes.

Madres y jardineras con frecuencia repiten que ellas ven la importancia de los talleres para que los niños no sufran -como les ocurrió a ellas- con la educación sexual que reciben. Insisten en la franqueza, la naturalidad, la tranquilidad con que deben ser abordados los temas referentes a la sexualidad humana.

Dentro del enfoque liberador de la educación pre-escolar, puede decirse que uno de sus fundamentos es la continuidad entre el proceso de educación dado por la familia y por el Hogar Infantil. Tanto en "Camitas Blancas" como en "Los Chircales" existe la conciencia acerca de la importancia de lograr la participación de los padres, y es en el primero de estos Hogares en donde más encontramos desarrollado este proceso.

\section{Sugerencia metodológica}

Queremos subrayar la importancia de llevar a cabo observaciones de los procesos pedagógicos, aunque en el caso de este estudio no tuvimos tiempo suficiente para ampliarlas. Pero, como lo revela el análisis anterior, es necesario no sólo interrogar a los 
jardineros y adultos sobre sus relaciones con los niños, sino observar y clasificar en lo posible esas relaciones, tal como ellas ocurren al nivel de lo cotidiano en la realidad.

Al iniciar este estudio, no habíamos reflexionado suficientemente sobre la manera o el método que podría utilizarse para hacer estas observaciones, en forma tal que no sólo sirvieran a un propósito de conocimiento, sino precisamente de transformación de las relaciones adultos-niños dentro de los centros pre-escolares.

Pensamos ahora que sería posible hacer grabaciones durante distintos períodos de las diversas actividades llevadas a cabo con los niños, en forma plenamente compartida con los jardineros que quisieran participar en una experiencia de este tipo. Si ellos pudieran grabar sus intervenciones con los niños, reflexionar sobre esas intervenciones, con la ayuda de observadores entrenados en las ciencias sociales, con el propósito de conocer mejor su propia conducta y lograr transformaciones convenientes para los niños y para los mismos adultos, esas observaciones serían un vehículo a la vez de conocimiento y práctica. Se lograría por ejemplo, pasar poco a poco de conductas de control y dominio, a las de juego, instrucción, conversaciones, y creemos que esto significaría un adelanto enorme para la socialización de los niños. Naturalmente que para ello se necesitarían algunas condiciones básicas como espacios en los cuales los niños pudieran moverse más libremente, juguetes y mobiliarios adecuados, la reducción del número de niños por jardinero, la capacitación de éstos en cuanto a metas de verdadero desarrollo del niño y de su quehacer ocupacional.

Re-descubrir con las jardineras en dónde se ubican sus interacciones con los niños, como modificarlas para respetar la autonomía del niño e impulsar su creatividad y desarrollo pleno, debieran ser las metas que el ICBF y las entidades administradoras de estos Hogares Infantiles se propusieran, si es que el Estado y las entidades comprometidas del sector privado en este esfuerzo, asumen con responsabilidad el cuidado y la educación de la población de estos niños de los sectores pobres de la ciudad.

\section{BIBLIOGRAFIA}

Center for Educational Research and Innovation. (1982). Caring for Young Children. An Analysis of Educational and Social Services. OECD. París.

CERDA, H. (1981). Pasado y presente de la educación pre-escolar en Colombia. Universidad Pedagógica Nacional. Bogotá.

LAZAR, I. et al. (1977). The Persistence of Pre-School Effect. Washington, D.C. MORTON, A. (1962). Life and Ideas of Robert Owen. Londres.

SALAZAR, M.C. (1983). El bienestar del niño y las políticas del estado. Informe de avance. Universidad Nacional de Colombia. Bogotá.

(1984). Educación pre-escolar: la definición social de la primera niñez. Revista Colombiana de Educación, primer semestre: pp. 49-7 6. Bogotá.

TAYLOR, P.H. el al. (1972). A Study of Nursery Education. Shools' Council Working Paper No. 41. Londres.

WOOD, D. et al. (1980). Working With Under Fives. Londres. 